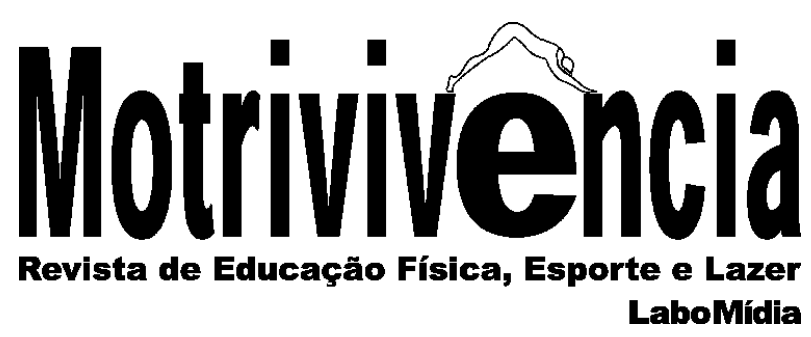

\title{
As condições para a Educação Física em escolas técnicas estaduais paulistas: um estudo sobre os recursos e a infraestrutura escolar
}

\section{RESUMO}

Apresenta um breve estudo sobre a infraestrutura escolar e os recursos para as aulas de Educação Física no ensino médio e integrado, em um grupo de 19 escolas técnicas estaduais [Etec] do interior paulista. A pesquisa de campo, de caráter exploratório, procura mapear a infraestrutura disponível para o desenvolvimento dos temas previstos na proposta curricular destas unidades escolares, propondo um módulo de recursos essenciais que poderiam ser disponibilizados em todo o Estado de São Paulo.

PALAVRAS-CHAVE: Educação física; Infraestrutura escolar; Ensino médio
Pedro Hernandes Neto

Pós-Graduado em Ensino e Aprendizagem de Jovens e

Adultos

Centro Paula Souza - Etec hernandes.pedro@gmail.com

D. https://orcid.org/0000-0001-5532-7797

Paulo Roberto Prado Constantino Doutor em Educação Centro Paula Souza / Unesp / UAP pconst2@gmail.com D. 1 https://orcid.org/0000-0002-4612-4063 
The conditions for Physical Education in state technical schools of São Paulo: a study on resources and school infrastructure

\begin{abstract}
This article presents a brief study about the school infrastructure and the resources available for Physical Education classes in high school and integrated, in a group of 19 technical schools [Etec] in the State of São Paulo, Brazil. Field research and exploratory, seeks to map the infrastructure available for the development of the themes foreseen in the curriculum of these schools, proposing a module of essential resources that should be available throughout the State of São Paulo.
\end{abstract}

KEYWORDS: Physical education; School infrastructure; High school

\title{
Las condiciones para la Educación Física en escuelas técnicas estatales paulistas: un estudio sobre los recursos y la infraestructura escolar
}

\section{RESUMEN}

Presenta un breve estudio sobre la infraestructura escolar y los recursos disponibles para las clases de Educación Física en la enseñanza media e integrada, en un grupo de 19 escuelas técnicas estatales [Etec] del interior paulista. La investigación de campo, de carácter exploratorio, busca mapear la infraestructura disponible para el desarrollo de los temas previstos en la propuesta curricular, proponiendo un módulo de recursos esenciales que deberían estar disponibles en toda provincia.

PALABRAS-CLAVE: Educación física; Infraestructura escolar; Enseñanza media 


\section{INTRODUÇÃO}

$\mathrm{O}$ artigo relata uma pesquisa que verificou a infraestrutura escolar disponível para as aulas de Educação Física no ensino médio e integrado, em um grupo de 19 escolas técnicas estaduais [Etec] do interior paulista. Ao mapear os recursos dispostos para o desenvolvimento dos temas previstos na proposta curricular destas unidades escolares, esperava-se também destacar um módulo de infraestrutura e recursos materiais essenciais que poderiam ser permanentemente oferecidos às escolas públicas de todo o Estado de São Paulo.

Sendo o pesquisador e primeiro autor também docente neste tipo de escola, intentou-se uma contribuição para o incentivo da educação básica e profissional pública, ao assinalar as condições de infraestrutura disponíveis para a educação física dos alunos de ensino médio e integrado nas Etecs.

O pleito justifica-se pela amplitude do atendimento destas Etecs no ensino médio paulista e as novas demandas postas pela recente discussão da Medida Provisória n ${ }^{\circ} 746$ (SENADO FEDERAL, 2016). Sem retomar exaustivamente a importância das aulas ou da presença da Educação Física no Ensino Médio, concordamos em princípio com os apontamentos de Darido (2012b), que afirmava que

a Educação Física, ao lado dos demais componentes curriculares escolares, deva propiciar ao aluno o exercício da cidadania, buscando durante a prática pedagógica a formação do sujeito crítico, direcionado para a conquista de sua autonomia, por meio do conhecimento, reflexão e transformação da cultura corporal (DARIDO, 2012b, p.123-124).

Sem as condições materiais mínimas, as práticas pedagógicas certamente ficam prejudicadas. Mais do que mapear as dificuldades dos professores de educação física, como a pesquisa de Gaspari (2006), procurou-se revelar as condições das escolas técnicas estaduais paulistas, em um grupo composto por 19 escolas do interior do Estado, que representa aproximadamente 9\% do total de Etecs existentes no momento (CETEC, 2017), configurando-se em uma amostra confiável frente ao total de escolas disponíveis.

Destaque-se que no Brasil a Educação Física é acometida historicamente pela falta de respaldo dos gestores (DARIDO, 2012a) e dos sistemas públicos, incluindo a inobservância da infraestrutura e dos recursos materiais mínimos para o seu desenvolvimento. Para além desta falta de suporte específico, a autora segue afirmando que

o papel da Educação Física ultrapassa o ensinar esporte, ginástica, dança, jogos, atividades rítmicas, expressivas e conhecimento sobre o próprio corpo para todos, em seus fundamentos e técnicas [dimensão procedimental], mas inclui também os seus valores subjacentes, ou seja, quais atitudes os alunos devem ter nas e para as 
atividades corporais [dimensão atitudinal]. E, finalmente, busca garantir o direito do aluno de saber o porque dele realizar este ou aquele movimento, isto é, quais conceitos estão ligados àqueles procedimentos [dimensão conceitual] (DARIDO, 2012a, p.55).

Avançando sobre o mero exercício dos conteúdos procedimentais, que podem acarretar uma prática esportiva esvaziada de finalidades educacionais, existem dificuldades na inclusão deste conhecimento da Educação Física ampliado aos alunos do ensino médio propedêutico ou integrado à educação profissional técnica, o que seria “extremamente recente e [com] dificuldades na seleção, e na implementação de conteúdos relevantes" (DARIDO, 2012a, p.54), quer pelo desconhecimento dos professores, quer pela falta de atenção dispensada pelos sistemas educacionais.

A instituição pesquisada possui um currículo formal baseado em competências a serem desenvolvidas na educação básica (CETEC, 2012), ancorado em certos conhecimentos, habilidades e atitudes, quer nas turmas de ensino médio propedêutico ou nas integradas ao ensino técnico, possuindo a mesma carga horária de 80 horas por ano nas três séries. Alguns dos princípios listados por Francisco Cordão (2010) são identificados nas propostas destas escolas, como a adequação do perfil de conclusão dos cursistas às demandas contemporâneas, o destaque das competências pessoais e profissionais essenciais, a identificação dos conhecimentos, habilidades e valores que deveriam ser fundamentalmente trabalhados pela escola. No campo da Educação Física, estes temas mais amplos que apresentaremos mais adiante no quadro 2 - são dimensionados por Darido (2012a) como certos tipos de conhecimentos, habilidades e atitudes e sintetizados que podem ser verificados no quadro seguinte:

Quadro 1: Sinopse das dimensões fundamentais da Educação Física escolar.

\begin{tabular}{|c|c|c|}
\hline Dimensão Conceitual & Dimensão Procedimental & Dimensão Atitudinal \\
\hline $\begin{array}{l}\text { - Conhecer as transformações por que passou } \\
\text { a sociedade em relação aos hábitos de vida } \\
\text { (diminuição do trabalho corporal em função } \\
\text { das novas tecnologias) e relacioná-las com as } \\
\text { necessidades atuais de atividade física. } \\
\text { - Conhecer as mudanças pelas quais passaram } \\
\text { os esportes. Por exemplo, que o futebol era } \\
\text { jogado apenas na elite no seu início no país, } \\
\text { que o voleibol mudou as suas regras em } \\
\text { função da televisão, etc. } \\
\text { - Conhecer os modos corretos da execução de } \\
\text { vários exercícios e práticas corporais } \\
\text { cotidianas, tais como: levantar um objeto do } \\
\text { chão, sentar-se à frente do computador, } \\
\text { realizar um exercício abdominal } \\
\text { adequadamente, etc. }\end{array}$ & $\begin{array}{l}\text {-Vivenciar e adquirir alguns } \\
\text { fundamentos básicos dos } \\
\text { esportes, danças, ginásticas, } \\
\text { lutas, capoeira. Por exemplo, } \\
\text { praticar a ginga e a roda da } \\
\text { capoeira. } \\
\text {-Vivenciar diferentes ritmos e } \\
\text { movimentos relacionados às } \\
\text { danças, como as danças de } \\
\text { salão, regional e outras. } \\
\text {-Vivenciar situações de } \\
\text { brincadeiras e jogos. }\end{array}$ & $\begin{array}{l}\text { - Valorizar o patrimônio de } \\
\text { jogos e brincadeiras do seu } \\
\text { contexto. } \\
\text { - Respeitar os adversários, } \\
\text { os colegas e resolver os } \\
\text { problemas com atitudes de } \\
\text { diálogo e não violência. } \\
\text { - Predispor a participar de } \\
\text { atividades em grupos, } \\
\text { cooperando e interagindo. } \\
\text { - Reconhecer e valorizar } \\
\text { atitudes não } \\
\text { preconceituosas quanto aos } \\
\text { níveis de habilidade, sexo, } \\
\text { religião e outras. }\end{array}$ \\
\hline
\end{tabular}

Fonte: DARIDO (2012a, p.52-53). 
As diferenças conceituais entre o ensino médio propedêutico e o ensino técnico integrado ao médio foram dispensadas desta discussão, em razão destas Etecs manterem o mesmo tratamento dispensado à Educação Física em ambas modalidades - com a mesma carga horária nas três séries, além do fato de muitas escolas abrigarem o ensino médio e o integrado em funcionamento simultâneo, compartilhando os mesmos professores e as mesmas condições estruturais. Cabe, no entanto, o esclarecimento de que as preocupações com a formação geral e integral dos indivíduos estão presentes nas propostas das escolas técnicas analisadas, especialmente as relacionadas ao comprometimento com a formação humana integral, superando a ideia de um ser fracionado pela divisão social do trabalho e a distância entre a ação e a reflexão, numa formação que procura propiciar aos jovens a compreensão das dinâmicas sociais, políticas, econômicas e culturais, habilitando-os ao exercício autônomo e crítico para interferir nas atuais conjunturas sociais e do mercado de trabalho (BRASIL, 2004; BRASIL, 2011; CORDÃO, 2010).

Posto isto, a perspectiva adotada nesta investigação assume que estas dimensões ampliadas dos conhecimentos da educação física escolar (DARIDO, 2012a) só podem ser adequadamente desenvolvidas se uma estrutura mínima de espaços e recursos materiais estiver disponível aos professores.

\section{CARACTERIZAÇÃO DA INSTITUIÇÃO FOCALIZADA}

Em 2017, o Centro Paula Souza, uma instituição autárquica de educação profissional pública, possuía 222 Escolas Técnicas [Etecs] espalhadas por todo Estado de São Paulo. 22 destas escolas localizam-se na Regional de Marília e Presidente Prudente, como parte de uma divisão de supervisão educacional concebida para a organização das unidades. Nelas, 2937 alunos estão matriculados no Ensino Médio e 3788 em cursos técnicos [Administração, Agropecuária, Edificações, Florestas, Informática, Informática para Internet, Mecatrônica e Química, p. ex.] integrados ao Ensino Médio, totalizando um público de 6725 alunos atendidos (CETEC, 2017) no ano letivo.

Destas 22 Etecs, 19 concordaram em participar da pesquisa, por meio de termo de consentimento livre e esclarecido, que obedeceu aos padrões éticos e protocolos de investigação comumente adotados, preservando a identidade dos participantes.

Assumindo-se como uma pesquisa de caráter exploratório (TOZONI-REIS, 2009), a primeira providência foi analisar os planos de curso das habilitações integradas e a proposta do ensino médio disponíveis na instituição. Baseado nas habilidades previstas aos alunos e os 
conteúdos dispostos para as três séries, elaborou-se um checklist de infraestrutura [quadra poliesportiva, pistas de competição, quadras de areia, salas temáticas, etc.] e recursos materiais [bolas, cordas, cones, entre outros] essenciais para o desenvolvimento curricular de diferentes possibilidades da Educação Física, como jogos, esportes, ginástica, atividades rítmicas e expressivas, lutas ou atividades físicas de aventura (DARIDO, 2012a). Em segundo momento, optou-se por questionar os professores e gestores do grupo de 19 escolas técnicas estaduais das regiões administrativas de Presidente Prudente e Marília/SP, com o auxílio do instrumento constituído de questões abertas e fechadas, para verificar as condições disponíveis para as aulas de Educação Física. Nesta direção, as pesquisas de Patias et. al (2014), Viana et. al (2014), Silva e Damazio (2008), Martini (2003) nos serviram de inspiração e referências para a elaboração desta investigação.

Por questão de enfoque, foram excluídas questões ligadas às dificuldades de ensino ou condições individuais de trabalho dos professores, de modo que a pesquisa se detivesse somente no aspecto da infraestrutura disponível nas Etecs do grupo. Estes outros questionamentos mencionados se apresentam como oportunidade para pesquisas posteriores.

\section{ELABORAÇÃO DOS INSTRUMENTOS DE PESQUISA E LEVANTAMENTO DOS DADOS}

Como mencionado no tópico anterior, ao desempenhar uma análise textual das propostas curriculares dos ensinos médio e técnico da instituição, comuns às 222 escolas do Estado de São Paulo (CETEC, 2012), foi possível produzir uma matriz documental com os grandes temas e competências a serem desenvolvidas entre os alunos das três séries. Com base nestas informações oriundas da proposta curricular comum, os pesquisadores realizaram posteriormente um checklist de possíveis recursos e da estrutura necessária para o desenvolvimento das diferentes atividades pedagógicas previstas nas Etecs.

Com base neste módulo mínimo de recursos para a Educação Física, materializado no checklist, efetivou-se uma consulta por meio de questionários em formulários eletrônicos aos 19 professores de Educação Física. Estes professores puderam responder ao questionário no espaço de duas semanas, de modo online e assíncrono (MURRAY, 1997). Levou-se em consideração as quantidades mínimas de equipamentos e dispositivos necessários às turmas de 40 alunos, mais comuns nestas unidades escolares: 
Quadro 2: Grandes temas de EF a serem desenvolvidos no Ensino Médio e Integrado das Escolas Técnicas

Estaduais de São Paulo (CETEC, 2012) e os recursos mínimos sugeridos pelos autores.

\section{Grande temas a serem abordados nos currículos das três séries de Ensino Médio e Integrado}

Tema 1: Esportes coletivos nos âmbitos: educacional, participação e competição. Modalidades. As capacidades físicas, as técnicas e as regras. As questões de inclusão e gênero nos esportes coletivos. As relações de esporte e cultura. Competição $\mathrm{X}$ cooperação. Os princípios éticos e relações interpessoais no esporte.

Tema 2: Esportes individuais nos âmbitos: educacional, de participação e competição. Modalidades: as capacidades físicas, as técnicas e as regras. A questão da inclusão. Práticas indevidas (doping, posturas antidesportivas, entre outras). $\mathrm{O}$ acesso aos esportes individuais.

Tema 3: Esportes radicais nos âmbitos: educacional, de participação e competição. Esportes de ação (skate, parkour) e de aventura (rapel, arvorismo, etc.). As capacidades físicas, as técnicas e as regras. Espaço, materiais e segurança. A questão da inclusão. Como o esporte radical se apresenta na mídia.

Tema 4: Jogos e brincadeiras: da brincadeira ao esporte. As regras e a inclusão. Espaço e materiais. Competição X cooperação.

Tema 5: Ginástica e dança: conceitos e classificações. Comunicação verbal e não verbal. Técnicas e/ou regras. As questões de gênero e a inclusão. A dança e a cultura.

Tema 6: Ginástica e dança nos âmbitos: educacional, de participação e competição. Modalidades. As capacidades físicas, as técnicas e as regras. Equilíbrios e desequilíbrios. As questões de gênero e inclusão na ginástica e na dança.

Tema 7: Corpo e movimento: aparelho locomotor (anatomia). Sistemas e suas alterações (fisiologia). Obtenção/utilização de energia (bioquímica). Sistema de alavancas (biomecânica).

Tema 8: Corpo e saúde: crescimento e desenvolvimento (psicologia). Alimentação e hidratação (nutrição). Patologias (cardiovasculares, osteoarticulares...).

Tema 9: Corpo e qualidade de vida. Segurança e ergonomia. Lazer e trabalho. Meio ambiente consumo. Planejamento e gerenciamento de atividades físicas
Sugestões de módulos mínimos de materiais [para turmas de 40 alunos]

Quadra poliesportiva -20 coletes -10 bolas de borracha $\mathrm{n}^{\circ} 8-5$ bolas de futsal, 5 bolas de handball -5 bolas de vôlei -5 bolas de basquete -20 computadores com acesso à internet $-\mathrm{Tv} /$ projetor 10 cones -4 bolas de rugby -2 bolas de futebol americano

10 cabos de vassoura -10 raquetes de tênis -10 bolas de tênis -1 colchão para atletismo -5 bolas de medicine ball -1 mesa de tênis de mesa -4 raquetes de tênis de mesa - 10 bolas de tênis de mesa -10 bambolês -1 kit faixa elástica -1 boneco bob de silicone -5 cordas para pular

1 kit de slackline -5 caixotes de madeira -10 skates -10 pares de patins - 1 prancha de equilíbrio - 1 kit de rapel (rapel e arvorismo) - 10 capacetes -10 pares de joelheira - Quadra poliesportiva $-\mathrm{Tv} /$ Projetor

10 peões -5 cordas de 4 metros -2 carros de rolimã - tinta para demarcação -20 coletes -6 bolas de borracha $n^{\circ} 8$ - Quadra poliesportiva - 40 colchonetes - 1 rolo de barbante - 20 computadores com acesso à internet -5 cordas para pular

5 fitas de ginástica rítmica -5 bolas de ginastica rítmica -10 maças de ginástica rítmica -10 balizas de ginastica rítmica colchão de atletismo - caixa de som - 1 microfone - 1 videogame (XBOX-Kinect com o jogo Just Dance) - 20 steps - 20 minicamas elásticas $-\mathrm{TV}$ / Projetor -1 kit de slackline

5 fitas de ginástica rítmica -5 bolas de ginastica rítmica -10 maças de ginástica rítmica -10 balizas de ginastica rítmica colchão de atletismo - caixa de som - 1 microfone - 1 videogame (XBOX-Kinect com o jogo Just Dance) - 20 steps - 20 minicamas elásticas - Tv/ Projetor - 1 kit de slackline

1 Esqueleto tamanho natural - 1 mapa do corpo humano plástico 1 mapa do sistema muscular esquelético plastificado - 1 mapa nutricional -5 pares de halter $2 \mathrm{~kg}-\mathrm{Tv}$ ou projetor -20 computadores com acesso à internet

1 Esqueleto tamanho natural - 1 mapa do corpo humano plástico 1 mapa do sistema muscular esquelético plastificado - 1 mapa nutricional $-\mathrm{Tv}$ ou projetor - 20 computadores com acesso à internet

2 kits de esfigmomanômetro com estetoscópio - 2 oxímetros digitais -1 cadeira de tamanho padrão p/exemplos -1 mesa tamanho padrão adulto - 1 notebook - 1 vassoura - 20 computadores com acesso à internet $-\mathrm{Tv}$ ou projetor -1 Esqueleto tamanho natural - 1 mapa do corpo humano plástico - 1 mapa do sistema muscular esquelético plastificado

Fonte: AUTORES (2017).

Apoiados neste módulo mínimo de infraestrutura e recursos, os questionários foram enviados às Etecs por meio de formulários eletrônicos, para que os professores de educação física pudessem avaliar suas próprias escolas. Estes questionários continham um misto de questões 
fechadas e abertas, predominando as primeiras. Um teste-piloto de validação foi aplicado previamente em duas escolas e, conferidos os dados inicialmente coletados, estendeu-se a pesquisa às outras dezessete unidades.

Os resultados, essencialmente quantitativos, foram recebidos e tratados digitalmente, por meio de softwares geradores de planilhas eletrônicas, e debatidos à luz das categorias suscitadas a partir das temáticas curriculares investigadas, no recorte que apresentamos a seguir.

\section{ALGUNS RESULTADOS OBTIDOS}

Tratou-se de observar, de início, que 11 das 19 escolas eram consideradas agrícolas, e também dispunham de especificidades de infraestrutura que precisaram ser relevadas na pesquisa. Duas destas Etecs agrícolas mantinham dois campi - urbano e rural - e seus dados foram tabulados como apenas uma unidade escolar.

Quanto à infraestrutura dos ambientes educacionais das escolas disponíveis à EF, observouse a seguinte disposição, a exemplo dos mapeamentos realizados por Silva e Damasio (2008), Oliveira et al (2011), Patias et al (2014):

Gráfico 1: Número de escolas que dispõem dos ambientes educacionais requisitados pela Educação Física [assinalados na legenda à direita].
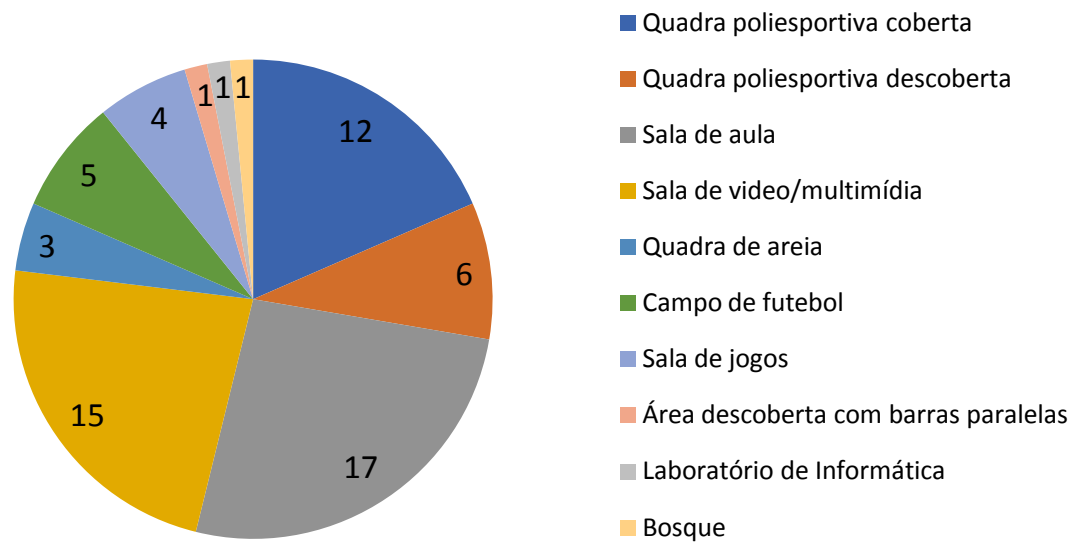

Fonte: AUTORES (2017).

Das 19 Etecs, 2 escolas não dispunham sequer de uma quadra poliesportiva coberta ou descoberta, e as atividades eram realizadas em exclusivamente em salas de aula, pátio de convivência ou no estacionamento dos automóveis. Laboratórios de informática e salas multimeios foram outros ambientes citados, além das salas de academia disponíveis em algumas das Etecs 
agrícolas. Por mais que exista um esforço para o reaproveitamento e a ressignificação dos espaços escolares, na perspectiva disposta por Oliveira et al. (2011), estas duas escolas encontram muitas dificuldades para o desenvolvimento da Educação Física entre seus alunos.

Observou-se mais adiante que os recursos materiais eram, em geral, disponibilizados, e os professores declararam empregá-los sempre que possível. No entanto, nem todos os recursos para o desenvolvimento integral das propostas estavam presentes. Tomando por exemplo o Tema 2 descrito no Quadro 2, 'esportes individuais', percebeu-se que poucas unidades escolares possuíam a quantidade mínima requerida para este tipo de trabalho:

Gráfico 2: Número de escolas que dispunham dos recursos materiais mínimos listados [à direita do gráfico] para o tema 2.

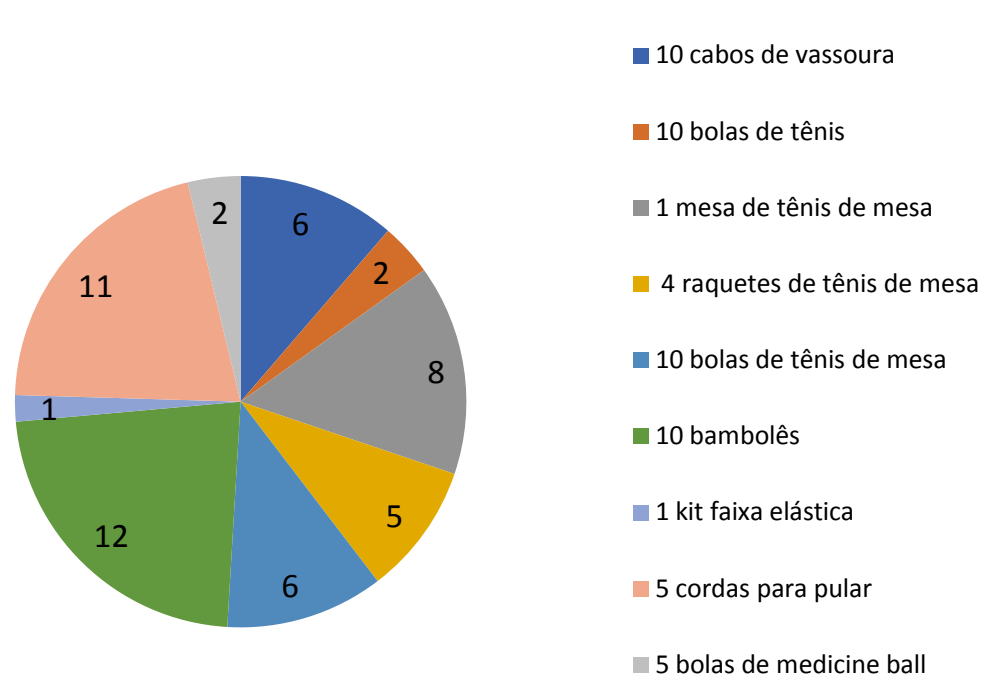

Fonte: AUTORES (2017).

De modo assemelhado, poucas escolas dispunham dos materiais mínimos para o desenvolvimento dos esportes individuais. Para os esportes radicais, os recursos são praticamente inexistentes:

Gráfico 3: Número de escolas que dispunham dos recursos mínimos listados [à direita] para o tema 3. 


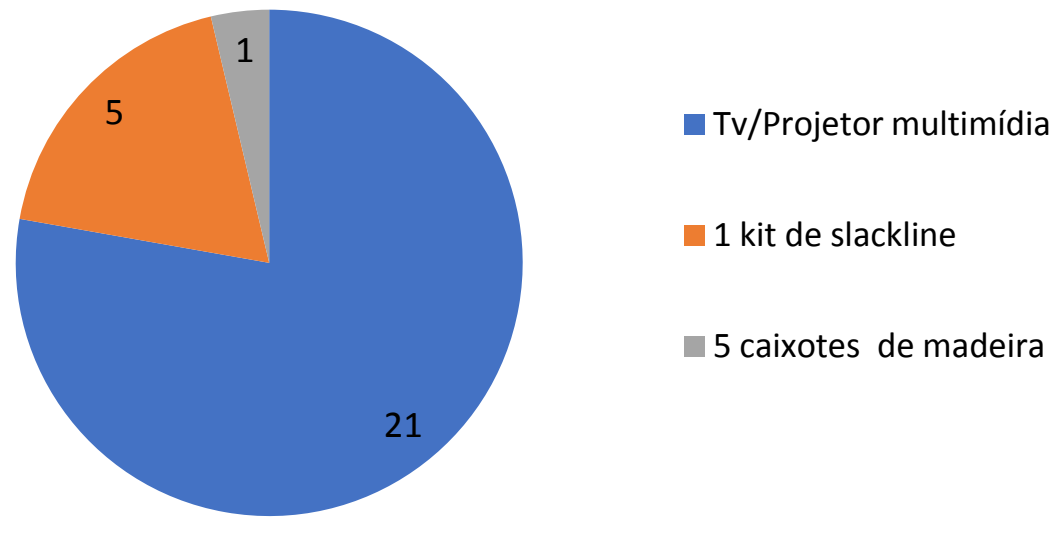

Fonte: AUTORES (2017).

Os importantes temas 7 e 8 , relacionados à saúde e qualidade de vida, também sofriam limitações quanto aos recursos disponíveis nas escolas, como aponta o gráfico 4:

Gráfico 4: Número de escolas que dispõem dos recursos mínimos listados [à direita] para os temas 7 e 8
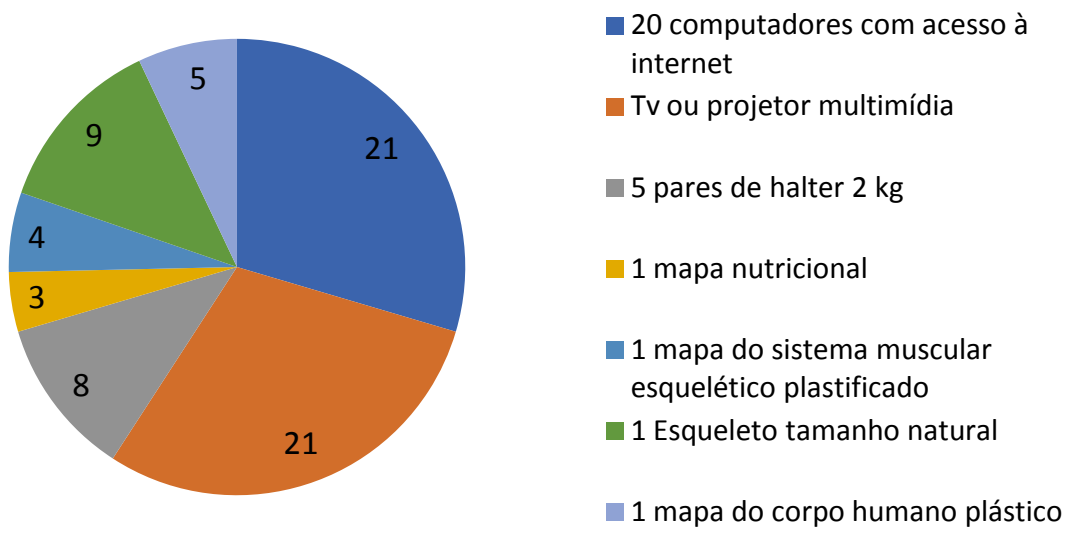

Fonte: AUTORES (2017).

Conforme a literatura aponta-nos, há uma ligação específica entre o contexto da escola, isto é, o que ocorre entre os sujeitos - alunos e professores - e a estrutura física em questão. Essa ligação seria redimensionada a todo tempo e em sentidos diversos para os envolvidos (OLIVEIRA, 2011).

Em razão dos limites e do escopo deste artigo, não foi possível relacionar todos os gráficos gerados pela análise dos questionários. Com base nesta amostragem, demonstra-se que as Etecs do grupo focalizado sofrem com a falta de recursos materiais, mais do que de infraestrutura e dos 
espaços físicos, e que o trabalho docente pode ser decisivamente comprometido pela ausência destes elementos, perspectiva corroborada por Silva e Damazio (2008) e Darido (2012c). Tal atenção deveria garantir que os temas relacionados à saúde, aos cuidados com o corpo e a prática desportiva fossem minimamente desenvolvidos.

\section{CONSIDERAÇÕES FINAIS}

Como se demonstrou, a diversidade dos conteúdos da Educação Física no âmbito do ensino médio e integrado precisa ser contemplada nas políticas públicas, na gestão e na organização dos espaços escolares públicos.

As informações obtidas revelam a necessidade de atenção dos entes públicos quanto ao investimento em parte destas 19 escolas, pois a ausência da infraestrutura mínima pode afetar o desenvolvimento dos alunos e sua aprendizagem em Educação Física, além de desmobilizar os professores em suas ações pedagógicas. Outras unidades escolares apresentaram-se minimamente supridas, o que possibilitou condições de trabalho mais adequadas aos seus professores. Estas desigualdades podem ser atribuídas, por certo, ao ritmo acelerado de expansão da rede de educação profissional paulista, que praticamente dobrou o número de escolas estaduais em funcionamento na última década (CETEC, 2017) sem necessariamente atentar-se à uma infraestrutura adequada para o desenvolvimento da disciplina no sistema público.

Quanto às atividades pedagógicas, grandes temas como esportes radicais e atividades individuais ficaram entre os mais prejudicados, segundo esta análise que empreendemos, com pouco espaço e condições para sua realização. Há, portanto, uma lacuna entre a proposta curricular formalizada para o ensino médio e integrado da instituição e as condições mínimas para sua efetivação. Aos professores resta, por vezes, um esforçado improviso para promover a variedade das práticas previstas para esta etapa da educação básica entre seus alunos.

Além de suscitar o debate sobre as condições da escola pública, ao final do estudo, pretendeuse o encaminhamento - como contributo aos setores responsáveis da instituição - de uma sugestão de módulo mínimo para as aulas do ensino médio e integrado, com os recursos e infraestrutura para o desenvolvimento curricular previsto nos documentos oficiais, bem como o atendimento do preconizado na Medida Provisória no 746/2016 (SENADO FEDERAL, 2017), que será consubstanciado na futura proposta de uma Base Nacional Curricular Comum do Ensino Médio ainda em discussão no presente momento - e nos referenciais curriculares nacionais em vigência. 


\section{REFERÊNCIAS}

BRASIL. Congresso Nacional. Lei n ${ }^{\circ}$ 9394/96. Estabelece as diretrizes e bases da educação nacional. Diário Oficial da União. Brasília, 24 de dezembro de 1996. Disponível em: $<$ http://www.planalto.gov.br/Ccivil_03/leis/L9394.htm>. Acesso em 03 abr. 2018.

. Decreto $\mathrm{N}^{\mathrm{o}} 5.154$ de 23 de julho de 2004. Regulamenta o $\S 2^{\circ}$ do art. 36 e os arts. 39 a 41 da Lei $\mathrm{n}^{\circ}$ 9.394, de 20 de dezembro de 1996, que estabelece as diretrizes e bases da educação nacional, e dá outras providências. Diário Oficial da União. Brasília, 26 de julho de 2004.

. Congresso Nacional. Lei Complementar $n^{\circ} 11.741 / 08$, de 16 de julho de 2008. Altera dispositivos da Lei no 9.394, de 20 de dezembro de 1996, que estabelece as diretrizes e bases da educação nacional, para redimensionar, institucionalizar e integrar as ações da educação profissional técnica de nível médio, da educação de jovens e adultos e da educação profissional e tecnológica. Diário Oficial da União. Brasília, 17 de julho de 2008.

CETEC. Atualização da proposta de currículo por competência para o Ensino Médio do Centro Paula Souza. 2012. Disponível em: $<$ http://www.cpscetec.com.br $>$. Acesso em: 01 mai. 2017.

. Banco de dados do ensino técnico no Centro Paula Souza. Disponível em:

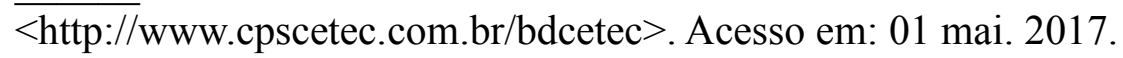

CORDÃO, Francisco Aparecido. Educação geral e formação na ótica das competências. In: REGATTIERI, Marilza; CASTRO, Jane Margareth (Orgs.). Ensino médio e educação profissional: desafios da integração. Brasília: UNESCO, 2010. p. 108-118.

DARIDO, Suraya Cristina. Educação Física na escola: conteúdos, duas dimensões e significados. In: UNIVERSIDADE ESTADUAL PAULISTA. Prograd. Caderno de formação: formação de professores - didática dos conteúdos. v. 6. São Paulo: Cultura Acadêmica, 2012a. p.51-75.

. Aspectos didáticos da educação física. In: UNIVERSIDADE ESTADUAL PAULISTA. Prograd. Caderno de formação: formação de professores - didática dos conteúdos. v. 6. São Paulo: Cultura Acadêmica, 2012b. p.112-126.

. Educação física na escola: realidade, aspectos legais e possibilidades. In:

UNIVERSIDADE ESTADUAL PAULISTA. Prograd. Caderno de formação: formação de professores - didática geral, v. 16. São Paulo: Cultura Acadêmica, 2012c. p. 21-33.

GASPARI, Telma Cristiane;. et al. A realidade dos professores de Educação Física na escola: suas dificuldades e sugestões. Revista Mineira de Educação Física. v. 14, p. 109-137, 2006.

MARTINI, Thábata Persinotti. Análise da realidade das aulas de educação física no ensino médio. Trabalho de conclusão de curso, Faculdade de Educação Física, Unicamp, 2003, 54 fl.

MURRAY, Peter J. Using virtual focus groups in qualitative research. Qualitative Health Research, v. 7, n. 4, nov. 1997, p. 542-554. Acesso restrito. Disponível em: < http://journals.sagepub.com/doi/abs/10.1177/104973239700700408>. Acesso em 21 set. 2017. 
OLIVEIRA, Camila Fagundes; SILVA, Lisandra Oliveira; MOLINA NETO, Vicente. Arquitetura escolar e o ensino de educação física: relações (im)possíveis. Pensar a Prática, Goiânia, v. 14, n. 2 , p. 01-10, maio/ago. 2011.

PATIAS, Bianca Conterato; et al. Infraestrutura e educação física escolar: ação e investigação. Anais do VII Congresso Sul Brasileiro de Ciências do Esporte. 2014. Disponível em: $<$ http://congressos.cbce.org.br/index.php/7csbce/2014/paper/view/6014/3152> Acesso em: 19 jun. 2017.

SENADO FEDERAL. Medida provisória $\mathbf{n}^{\mathbf{0}} \mathbf{7 4 6}$, de 2016. Institui a Política de Fomento à Implementação de Escolas de Ensino Médio em Tempo Integral, altera a Lei n ${ }^{\circ}$ 9.394, de 20 de dezembro de 1996, que estabelece as diretrizes e bases da educação nacional, e a Lei $n^{\circ} 11.494$ de 20 de junho 2007, que regulamenta o Fundo de Manutenção e Desenvolvimento da Educação Básica e de Valorização dos Profissionais da Educação, e dá outras providências. Disponível em: $<$ http://www25.senado.leg.br/web/atividade/materias/-/materia/126992>. Acesso em 01 jun. 2017.

SILVA, Maria Fatima Paiva; DAMAZIO, Marcia Silva. O ensino da educação física e o espaço físico em questão. Pensar a Prática, UFG, v. 11, n. 2, 2008.

TOZONI-REIS, Marília Freitas de Campos. Metodologia da pesquisa. 2.ed. Curitiba: IESDE Brasil AS, 2009.

VIANA, Daniele Cristina; et al. A realidade da Educação Física escolar em escolas rurais: uma análise das estruturas físicas designadas para a prática esportiva. EFDeportes.com - Revista Digital, ano 19, $\mathrm{n}^{\circ}$ 192, Buenos Aires, mai. 2014. Disponível em: < www.efdeportes.com/efd192/educacao-fisica-escolar-em-escolas-rurais.htm $>$ Acesso em: 01 jun. 2017. 


\section{NOTAS DE AUTOR}

\section{AGRADECIMENTOS}

Agradecemos aos diretores das unidades escolares envolvidas na coleta de dados.

\section{CONTRIBUIÇÃO DE AUTORIA}

Concepção do manuscrito: P. Hernandes Neto, P.R.P. Constantino.

Coleta de dados: P. Hernandes Neto.

Análise de dados: P. Hernandes Neto, P.R.P. Constantino.

Discussão dos resultados: P. Hernandes Neto, P.R.P. Constantino.

Produção do texto: P. Hernandes Neto.

Revisão e aprovação: P.R.P. Constantino.

\section{LICENÇA DE USO}

Os autores cedem à Motrivivência - ISSN 2175-8042 os direitos exclusivos de primeira publicação, com o trabalho simultaneamente licenciado sob a Licença Creative Commons Attribution Non-Comercial ShareAlike (CC BY-NC SA) 4.0 International. Estra licença permite que terceiros remixem, adaptem e criem a partir do trabalho publicado, desde que para fins não comerciais, atribuindo o devido crédito de autoria e publicação inicial neste periódico desde que adotem a mesma licença, compartilhar igual. Os autores têm autorização para assumir contratos adicionais separadamente, para distribuição não exclusiva da versão do trabalho publicada neste periódico (ex.: publicar em repositório institucional, em site pessoal, publicar uma tradução, ou como capítulo de livro), com reconhecimento de autoria e publicação inicial neste periódico, desde que para fins não comerciais e compartilhar com a mesma licença.

\section{PUBLISHER}

Universidade Federal de Santa Catarina. Programa de Pós-Graduação em Educação Física. LaboMídia - Laboratório e Observatório da Mídia Esportiva. Publicado no Portal de Periódicos UFSC. As ideias expressadas neste artigo são de responsabilidade de seus autores, não representando, necessariamente, a opinião dos editores ou da universidade.

\section{EDITORES}

Mauricio Roberto da Silva, Giovani de Lorenzi Pires, Rogério Santos Pereira. 


\section{HISTÓRICO}

Recebido em: Fevereiro/2018

Aprovado em: Maio/2018 